\title{
Flexural and Thermal Properties of Novel Energy Conservation Slotted Reinforced Concrete Beams
}

\author{
Gao Ma, ${ }^{1}$ Liang Huang, ${ }^{1}$ Libo Yan, ${ }^{2,3}$ Hui Wang, ${ }^{1}$ and Peng Yin ${ }^{1}$ \\ ${ }^{1}$ College of Civil Engineering, Hunan University, Changsha 410082, China \\ ${ }^{2}$ Department of Organic and Wood-Based Construction Materials, Technical University of Braunschweig, \\ Hopfengarten 20, 38102 Braunschweig, Germany \\ ${ }^{3}$ Centre for Light and Environmentally-Friendly Structures, Fraunhofer Wilhelm-Klauditz-Institut WKI, \\ Bienroder Weg 54E, 38108 Braunschweig, Germany
}

Correspondence should be addressed to Liang Huang; lianghuanghnu@gmail.com

Received 15 January 2016; Accepted 4 April 2016

Academic Editor: João M. P. Q. Delgado

Copyright (C) 2016 Gao Ma et al. This is an open access article distributed under the Creative Commons Attribution License, which permits unrestricted use, distribution, and reproduction in any medium, provided the original work is properly cited.

\begin{abstract}
Conventional solid reinforced concrete $(\mathrm{RC})$ beams were modified to slotted beams for consideration as thermal insulation structural components. The slotted beam consisted of an outer and an inner beam, respectively, with a slot located near the middle of the beam along its width direction for filling thermal insulation material. Flexural and thermal behavior of the slotted beams were investigated. Three RC reference solid beams and six slotted beams were fabricated and tested under four-point bending tests. The test results indicated that the failure mode of both slotted beams and the solid beams was flexural failure. However, the damage process of the slotted beams was different from that of the solid beams at the final loading stage. The moment curvature analysis indicated that the tensile reinforcement ratio of the outer and inner beams had an important effect on the flexural behavior, especially the ductility of the slotted beams. Thermal study indicated that the heat transfer coefficient of the slotted beam was greatly reduced and the thermal inertia factor increased a lot, compared with the solid beam. In addition, FE simulation results showed that a new frame structure using slotted beams exhibited obvious and attractive thermal insulation property.
\end{abstract}

\section{Introduction}

Building energy conservation is one of the most important energy-saving policies in developing and developed countries [1]. For a building, thermal bridge refers to a component with a relatively higher heart transfer than the surrounding parts, which leads to a significant reduction in the thermal insulation of the building. Thermal bridges generally exist in building structures $[2,3]$, such as frame structures, shear wall structures, and masonry structures. For a reinforced concrete (RC) frame structure, the beams and columns all contribute to thermal bridges. Generation and characteristics of thermal bridge are related to the material properties of the structure and the layout of the structure. In a building, its walls, windows, beams, and columns are the main components to generate thermal bridges. If these components can be designed to have an enhanced thermal insulation and reduced heat conduction performance, the issue of thermal bridges in building structures can be solved.
In general, the popular external wall thermal insulation can be classified into exterior insulation and inner insulation of the external wall. Inner insulation of external wall is a technique which uses thermal insulating layer on the inner surface of the external wall of a structure. Because the insulating layer hides inside the walls, this technique reduces the usable area of the structure, affects the redecoration, and generates mildew and moisture condensation in the walls. To date, the technique of exterior insulation of the external wall is still not so mature; for instance, the construction is difficult and the energy-saving investment is high. Meanwhile, the outside insulation layer is under the risk of fire disaster, is easy to drop off and gets seepage in rainy weather; it is difficult to paste ceramic tile or hang marble on the thermal insulating layer and the durability of the exterior insulation system is reduced because it is directly exposed to the outdoor atmosphere. To solve these problems, self-thermal insulation building blocks such as thermal insulation concrete block [4], 


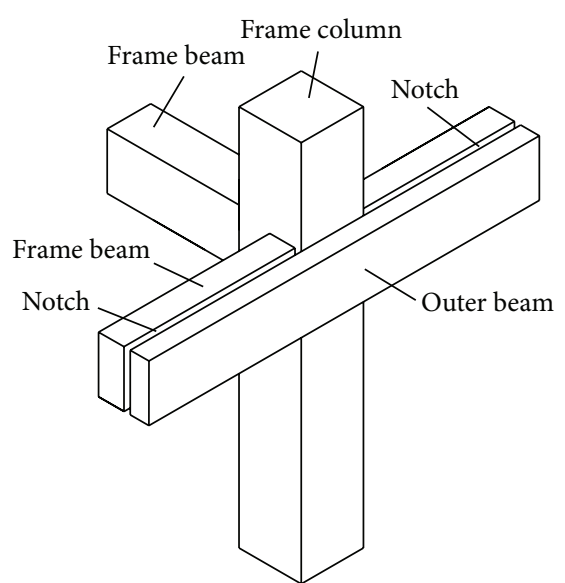

(a)

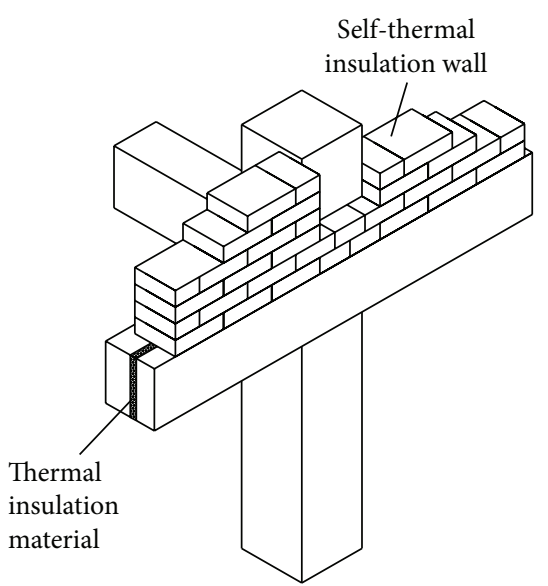

(b)

FIGURE 1: Sketch of energy conservation slotted beam-wall system: (a) constructional details of the slotted beam and (b) the view after selfthermal insulation wall constructed.

hollow block [5], and vacuum insulation window [6-8] have been developed and adopted in practical application.

For RC frame structures, the use of self-thermal insulation building blocks and vacuum insulation windows prevents the walls and the windows from generation of thermal bridges, and hence thermal bridges mainly exist in beams and columns. This paper presents a new type of energy conservation slotted beam-wall system, as shown in Figure 1. Conventional reinforced concrete (RC) beams are modified into slotted beams, and the gap between the outer and inner beams is used to fill with thermal insulation materials. Selfthermal insulation wall is constructed on the slotted beams. It is obvious that this type of slotted beam-wall structure possesses a favourable thermal insulation property, because the thermal bridges at the beams and columns can be reduced effectively. Meanwhile, this new energy conservation wall system is convenient in construction.

In this paper, the feasibility of slotted RC beams as thermal insulation structural components was investigated. Three reference solid beams and six slotted beams were fabricated and tested under four-point bending test. The flexural behavior of the slotted beams was investigated in detail, including failure mode, load-deflection response, and moment curvature analysis. The effects of reinforcement ratio and width ratio of the inner beam to the outer beam on the flexural behavior of slotted beams were investigated, and then a design method for slotted beam was proposed. The thermal properties of the slotted and solid RC beams were analysed and compared. In addition, the thermal performance of the slotted beam-wall system was investigated through finite element method (FEM) analysis.

\section{Experimental}

2.1. Fabrication of Beams. In order to study the flexural behavior of the slotted beams, a total of 9 beams were designed and constructed, including 6 slotted beams and 3 reference solid beams. As displayed in Figure 2(a), the width of the slot is $30 \mathrm{~mm}$ and the distance from the slot to the left/right end is $150 \mathrm{~mm}$. The total width of the outer and inner beam of a slotted beam is $250 \mathrm{~mm}$, which is equal to the width of the solid beam. The depth and the length of the slotted beams are identical to those of the reference solid beams, with a depth of $250 \mathrm{~mm}$ and a length of $3000 \mathrm{~mm}$. The inner and the outer beam were designated as "beam A" and "beam B", respectively (Figure $2(\mathrm{a})$ ).

The reinforcement details of the tested beams are also shown in Figure 2. Detailed descriptions of the specimens are given in Table 1. Constructional reinforcement was used for the compressive region of the beam. The following aspects were considered in the tests: the reinforcement ratio of beam $\mathrm{A}$ and beam $\mathrm{B}$ and the width ratio $\left(b_{\mathrm{A}} / b_{\mathrm{B}}\right)$. The amount of the tensile reinforcement, the compressive reinforcement, and the shear reinforcement of the slotted beam were designed to be close to those of the corresponding reference solid beam, in order to facilitate comparison of the results. In Table 1, SB denotes the slotted beams and RB denotes the reference solid beams. The number behind SB denotes the section type, reflecting the width ratio $\left(b_{\mathrm{A}} / b_{\mathrm{B}}\right)$. The diameter of the longitudinal reinforcement rebar in beam $B$ is given at the last part of the specimen denomination. For example, SB1-14 represents a slotted beam with section type 1 , and the diameter of the rebar in beam B is $14 \mathrm{~mm}$. The reference solid beam for SB1-14 and SB2-14 is RB-14.

The mix proportion of concrete is listed in Table 2. The concrete compressive strength of each specimen was determined from the compression test on $150 \times 150 \times$ $300 \mathrm{~mm}$ standard concrete prism. Deformed steel was used for longitudinal reinforcement and plain steel was used for hoop reinforcement. Mechanical properties of the rebars are given in Table 3.

2.2. Experimental Program. Figure 3(a) shows a slotted beam under four-point bending test. The locations of the two concentrated loads and the supports are given in the schematic view in Figure 3(b). Dial indicators with an accuracy of $0.01 \mathrm{~mm}$ were fixed at the bottom of the beams to record the deflection responses, as shown in Figure 3(a). For slotted 


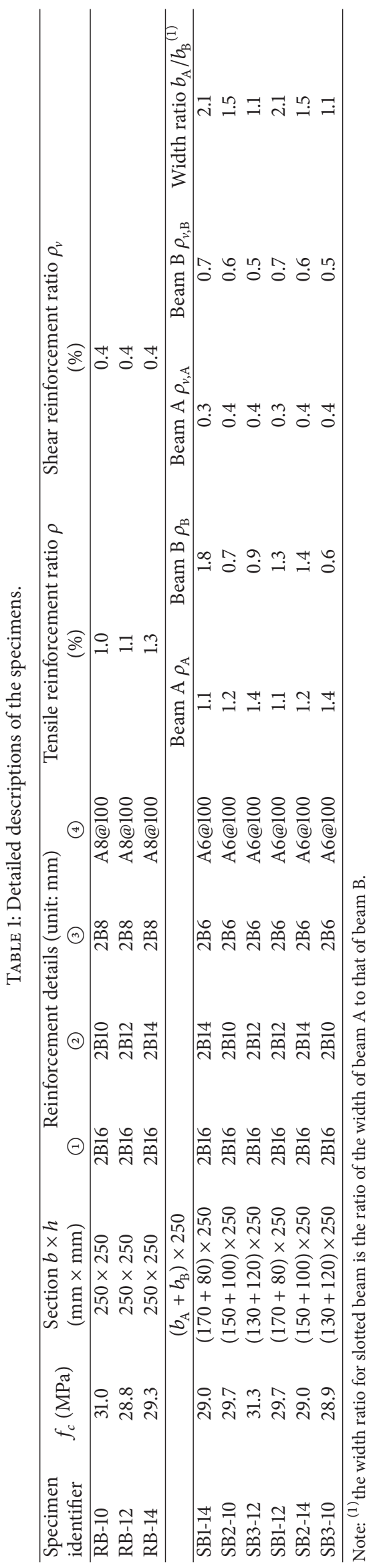




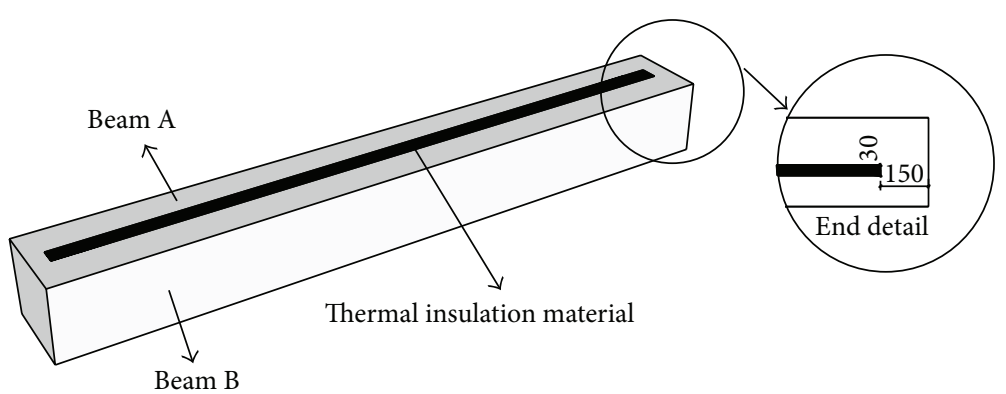

(a)
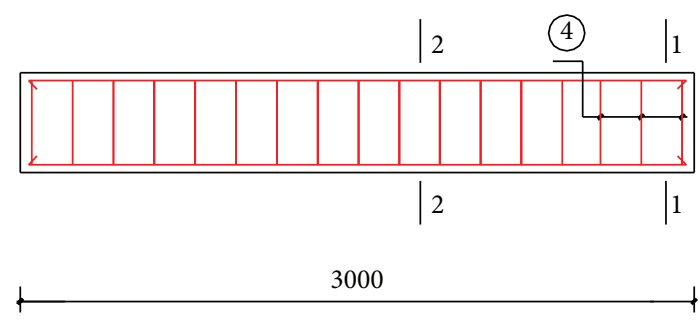

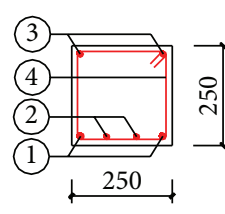

$1-1$

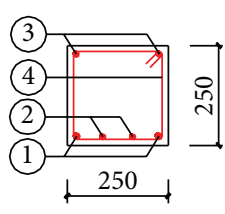

$2-2$

(b)
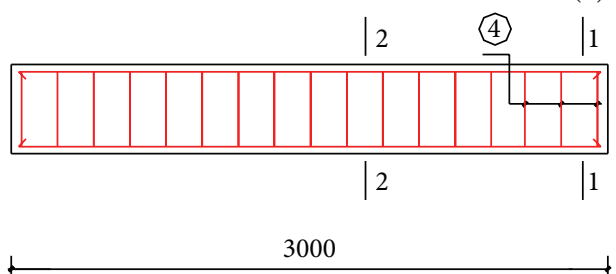

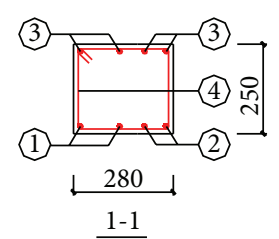

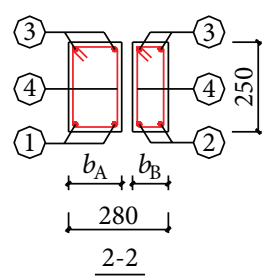

(c)

FIGURE 2: Specimen dimensions and reinforcement: (a) sketch of a slotted beam; (b) solid RC beam; and (c) slotted beam (units: mm).

TABLE 2: Concrete mix proportion.

\begin{tabular}{lcccc}
\hline Component & Water & $\begin{array}{c}\text { Ordinary } \\
\text { Portland cement }\end{array}$ & Sand Coarse aggregate \\
\hline Quantity $\left(\mathrm{kg} / \mathrm{m}^{3}\right)$ & 173 & 392 & 487 & 1249 \\
\hline
\end{tabular}

beams, two dial indicators were used for each position to record the deflection of beam A and beam B, respectively. Dial indicators were also fixed at the left and right ends of each beam to record the displacement of the beam ends. Crack width observation instrument with an accuracy of $0.02 \mathrm{~mm}$ was carefully used to measure the maximum crack width of the beams. The spacing between the cracks and the crack number were also measured and marked at load intervals. Strain gauges on the tensile rebars and concrete surface at the middle span of the beams were recorded. During the test, the loads corresponding to the appearance of the first tensile crack and tensile rebar yielding were also recorded. The fourpoint bending test was conducted according to the standard for test method of concrete structures in China [9].

\section{Four-Point Bending Test Results and Analysis}

3.1. Crack and Damage Patterns of the Solid and Slotted Beams. The damage patterns of the solid beams and slotted beams
TABLE 3: Mechanical properties of the reinforcement rebars.

\begin{tabular}{lcc}
\hline Material type & Yield strength (MPa) & Ultimate strength (MPa) \\
\hline B10 & 382 & 536 \\
B12 & 376 & 556 \\
B14 & 379 & 543 \\
B16 & 385 & 549 \\
A6 & 346 & 464 \\
A8 & 352 & 478 \\
\hline
\end{tabular}

are shown in Figure 4. For the solid beams, the first crack was tensile crack and appeared in the flexural zone near the middle span of the beam. With an increase of the load, new tensile cracks appeared and the former tensile cracks developed into the upper part of the beam. Shear cracks were observed near the ends of the beams at the late loading stage, because the shear force and moment were both significant in this region. Concrete crush was observed on the compressive region of the middle span of the beam at the final loading stage. Therefore, it can be concluded that the final failure mode of the solid beams was the flexural failure.

For the slotted beams, the first tensile crack appeared on the surface of the middle span of beam $A$ and beam $B$, respectively. Then, the cracks in both beam $A$ and beam $B$ developed on the surfaces of the beams with the increase 


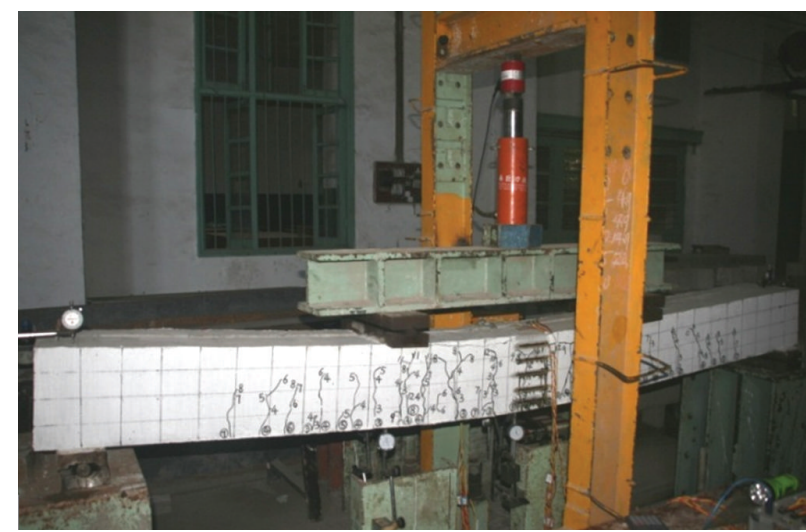

(a)

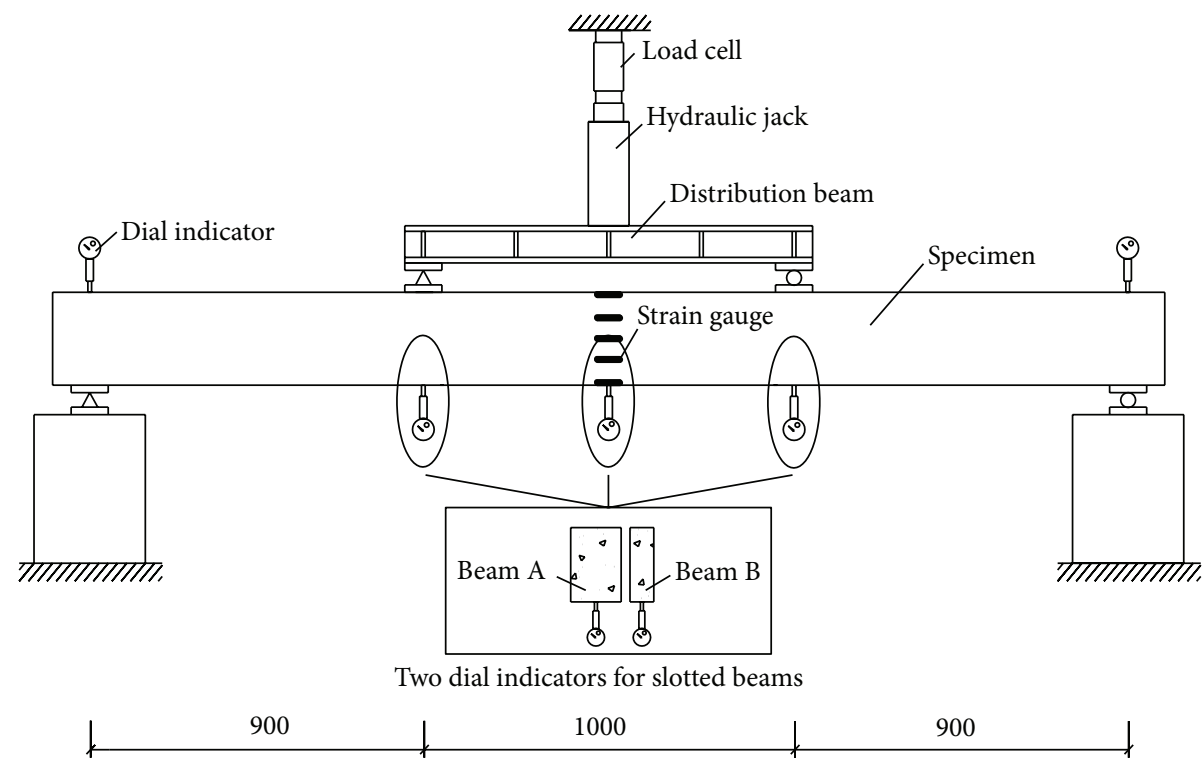

(b)

Figure 3: Four-point bending test system of the RC beams: (a) photo of the test devices; (b) sketch of the test devices (units: mm).

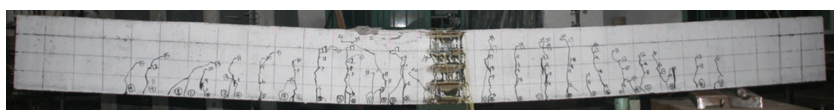

(a)
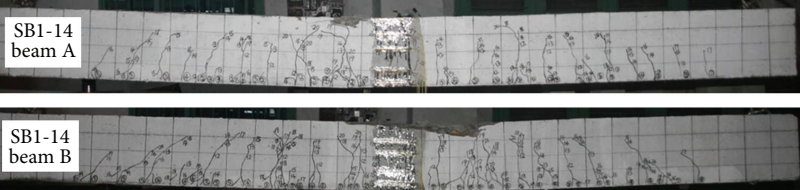

(b)

Figure 4: Damage patterns of the beams: (a) RB-14 and (b) SB1-14.

of the load. At the final loading stage, concrete crushing began to appear in the compression region at the middle span of beam A and beam B. The mechanical behavior of beam $\mathrm{A}$ and mechanical behavior of beam $\mathrm{B}$ of a slotted beam were different from each other, due to the difference in the section dimension and reinforcement ratio. Since the deflections of beam A and beam B at the middle span were almost similar to each other caused by the loading scheme used in the test, the concrete crushing at the middle span of beam A and beam B did not appear simultaneously, resulting in the different ductility behavior of beam $\mathrm{A}$ and beam $\mathrm{B}$. The failure process of the two parts of the slotted beams observed during the final loading stage demonstrated this inference. More in-depth analysis concerning the ductility behavior of the two parts of the slotted beams will be given in Section 3.3. Though the mechanical behavior of beam A and beam B was different, severe concrete crushing was observed at the middle span of both beam $A$ and beam $B$ at the failure stage, indicating that the final failure model of the slotted beams was flexural failure. Therefore, it can be concluded that 
TABLE 4: Test results of the specimens.

\begin{tabular}{|c|c|c|c|c|c|}
\hline $\begin{array}{l}\text { Specimen } \\
\text { identifier }\end{array}$ & $\begin{array}{l}\text { Yielding deflection } \\
\Delta_{y}(\mathrm{~mm})\end{array}$ & $\begin{array}{l}\text { Yielding load } \\
(\mathrm{kN})\end{array}$ & $\begin{array}{c}\text { Peak load } \\
\text { capacity }(\mathrm{kN})\end{array}$ & $\begin{array}{c}\text { Ultimate deflection } \\
\qquad \Delta_{u}(\mathrm{~mm})\end{array}$ & $\begin{array}{c}\text { Ductility ratio } \\
\mu_{\Delta}{ }^{(1)}\end{array}$ \\
\hline RB-10 & 11.0 & 98.6 & 113.0 & 69.6 & 6.3 \\
\hline RB-12 & 11.9 & 108.0 & 120.6 & 67.1 & 5.6 \\
\hline RB-14 & 12.3 & 128.6 & 141.0 & 60.7 & 5.0 \\
\hline SB1-14 & 12.3 & 129.5 & 132.9 & 51.2 & 4.2 \\
\hline SB2-10 & 14.9 & 106.7 & 109.9 & 56.1 & 3.8 \\
\hline SB3-12 & 12.2 & 108.6 & 120.0 & 52.6 & 4.3 \\
\hline SB1-12 & 12.6 & 113.8 & 118.9 & 64.4 & 5.1 \\
\hline SB2-14 & 12.4 & 129.5 & 135.0 & 61.2 & 4.9 \\
\hline SB3-10 & 14.8 & 96.6 & 103.8 & 46.8 & 3.2 \\
\hline
\end{tabular}

Note: ${ }^{(1)}$ the ductility of the beam was calculated by $\Delta_{u} / \Delta_{y}$.

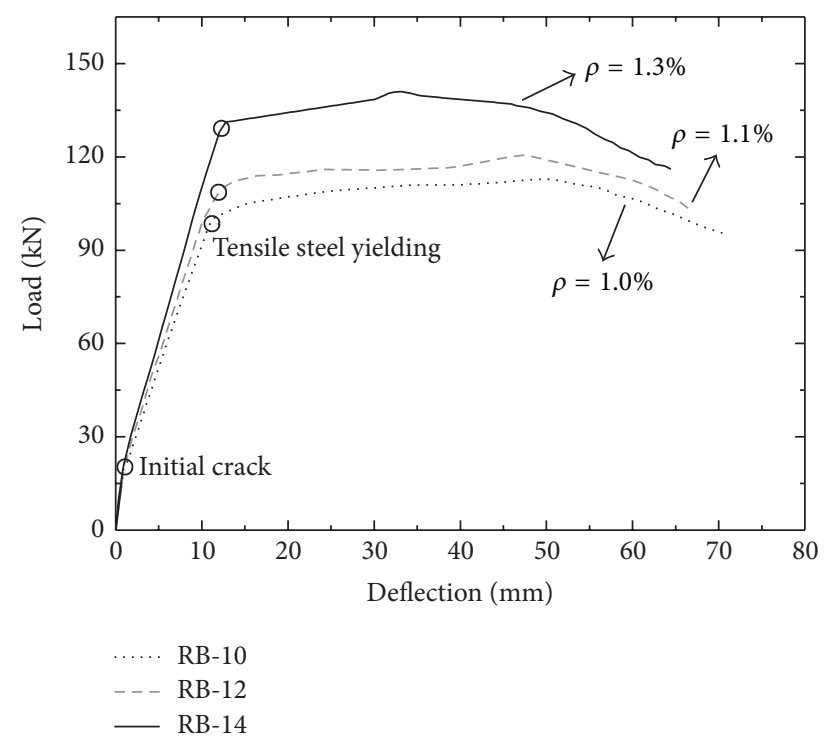

Figure 5: Deflection curves of the solid beams.

the damage process of the slotted beams exhibited a certain difference from that of the solid beams.

3.2. Load-Deflection Curve Analysis. The flexural loaddeflection curves of the solid RC beams are given in Figure 5. These curves can be divided into three stages: precrack stage, preyield stage, and postyield stage. The initial linear portion of the curves shows that the stiffness of the beams remained constant prior to the cracking load. The initial cracking point of the three solid beams were almost identical, because the section dimension and the concrete strength of the three beams were almost the same. After the cracking load, the stiffness of the solid beams decreased gradually, as displayed in Figure 5. The yield strength and load capacity increased with the increase in the tensile reinforcement ratio. Because all the three beams were under-reinforced beams, with tensile reinforcement ratio of $1.0 \%, 1.1 \%$, and $1.3 \%$, respectively, obvious ductility behavior can be observed from the loaddeflection curves. The mechanical properties of the solid beam are given in Table 4, where the yielding load was determined when the strain gauges pasted on tensile steel reached yielding strain; the ultimate deflection corresponded to the displacement when vertical load decreased to $85 \%$ of the peak load capacity. In Table 4 , it can be found that the ductility ratio of the solid beams decreased with the increase in the tensile reinforcement ratio.

It was difficult to fix load cells at the two fulcrums of the steel distribution beam during the four-point bending test, so the concentrated force applied on the two parts of the slotted beams was not measured during the tests. Because both beam $A$ and beam $B$ entered into nonlinear stage after cracking point, it was improper to calculate the actual load applied on each part of the two beams based on the initial elastic crosssection stiffness of each beam. For a slotted beam, the dial indicators showed that the deflections of beam $A$ and beam $B$ were almost the same. Therefore, the total load applied on the top of the distribution beam and the average readings of the dial indicators were used to depict the load-deflection curves of the slotted beams.

Figure 6 shows the deflection curves of the slotted beams and the corresponding solid beams. Before the deflection curves entered into the descending branch, the loaddeflection curves of the slotted RC beams were close to that of the corresponding solid RC beam, indicating that the cracking load and yielding load of the slotted beams were almost similar to those of the corresponding solid beam. For SB2-10, the ductility of the load-deflection curves of the slotted beams was lower than that of the corresponding solid RC beam RB-10, and the ductility of SB3-10 became obviously lower than that of SB2-10. Obvious lower ductility was also observed for the slotted beams SB3-12 and SB1-14, comparing with their corresponding solid RC beam. However, the loaddeflection curves of SB1-12 and SB2-14 were close to that of the corresponding solid beam and it can be found that the difference between the reinforcement ratio of beam $A$ and beam $B$ of SB1-12/SB2-14 was obviously smaller than that of the other slotted beams. This experimental phenomena indicated that the reinforcement ratio of beam $A$ and beam $B$ had an obvious effect on the flexural behavior of the slotted beams. Detailed analysis for this phenomena will be given in Section 3.3. 


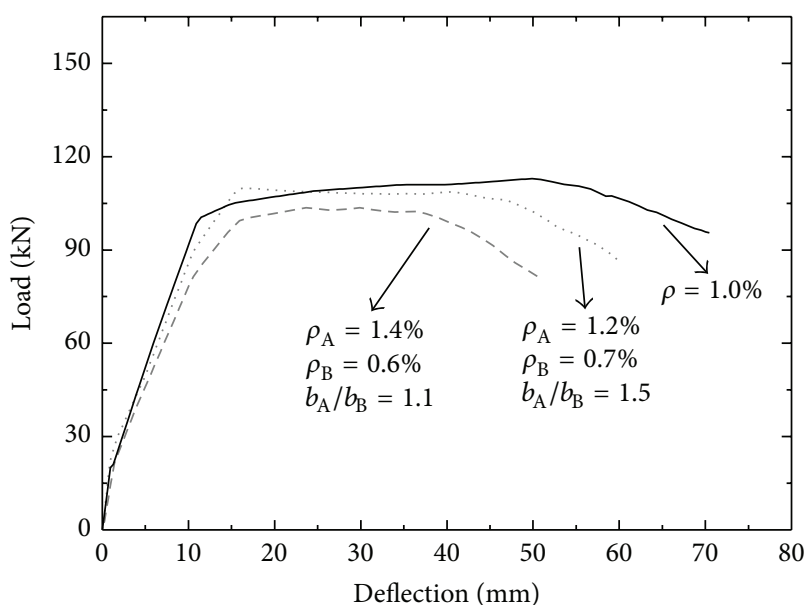

SB2-10

- - - SB3-10

- RB-10

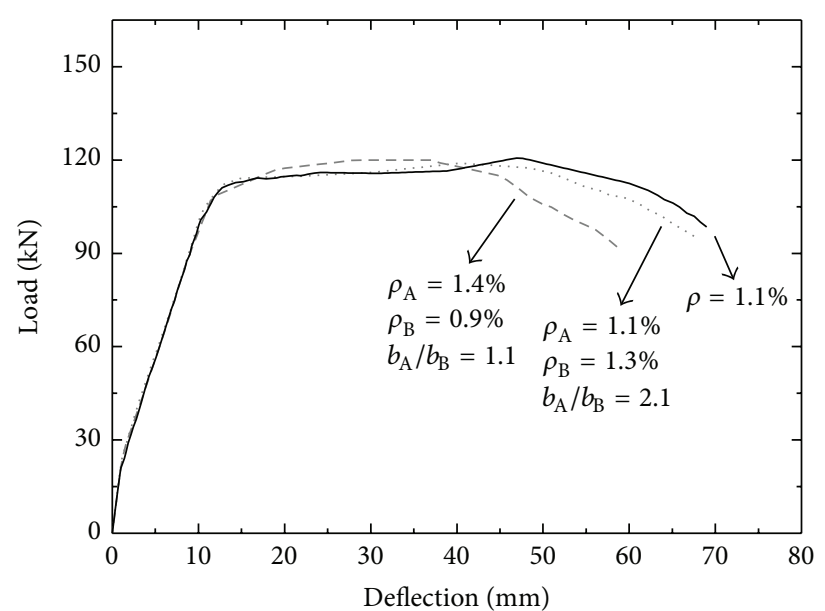

SB1-12

- - - SB3-12

- RB-12

(a)

(b)

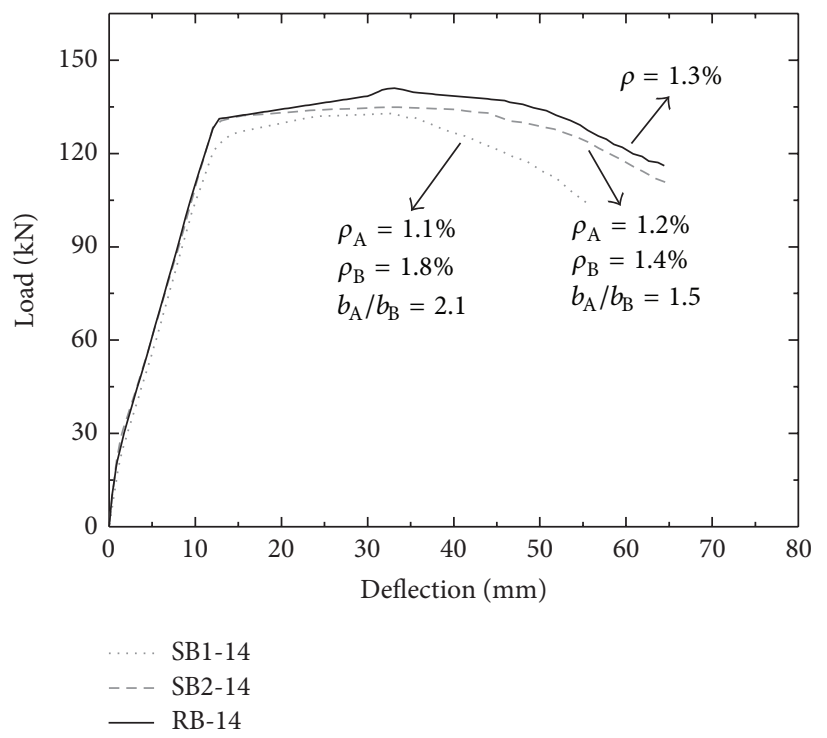

(c)

FIgURE 6: Load-deflection curves of the slotted beams: (a) SB2-10 and SB3-10; (b) SB1-12 and SB3-12; and (c) SB1-14 and SB2-14.

3.3. Moment Curvature Analysis. The moment curvature relationship of a beam section can be calculated by using the information of the beam section size, the reinforcement, and the stress-strain curves of the material. In the calculation, the stress-strain curves of the steel rebars obtained from the axial tensile tests were used, and the stress-strain curves of the concrete followed the modified Kent-Park model [10, 11]. The calculation process of moment curvature relationship of a beam section was described in detail in relevant reference [12] and hence is omitted here. The moment curvature curve of all the solid beams is shown in Figure 7, and the values corresponding to the yield point, peak point, and failure point are given in Table 5. The results show that the moment capacity of the beam section increased with the increase in the reinforcement ratio; however, the curvature ductility exhibited a decrease trend, because increased tensile reinforcement ratio can lead to an increase of the height of the compressive region (resulting in decreased curvature).

The deflection curves of beam A and beam B for a slotted beam during the tests were almost the same, based on the readings of the dial indicators fixed on the bottom surfaces of beam A and beam B. Therefore, it can be inferred that the curvatures of the section at the middle span of the two beams are almost identical during the tests, based on the deflection theory of beam. Hence, the moment curvature curve of the entire slotted beam can be derived through superimposing the moment of beam A and beam B at a certain curvature. The moment curvature curves of the two parts of the slotted beams are shown in Figure 8, where the moment curvature 
TABLE 5: Characteristic points on the calculated moment curvature curves of the specimens.

\begin{tabular}{|c|c|c|c|c|c|}
\hline $\begin{array}{l}\text { Specimen } \\
\text { identifier }\end{array}$ & $\begin{array}{l}\text { Yielding curvature } \\
\phi_{y}(\mathrm{rad})\end{array}$ & $\begin{array}{l}\text { Yielding moment } \\
(\mathrm{kN} \cdot \mathrm{m})\end{array}$ & $\begin{array}{c}\text { Peak moment } \\
\text { capacity }(\mathrm{kN} \cdot \mathrm{m})\end{array}$ & $\begin{array}{c}\text { Ultimate curvature } \\
\phi_{u}(\mathrm{rad})\end{array}$ & $\begin{array}{c}\text { Ductility ratio } \\
\mu_{\phi}{ }^{(1)}\end{array}$ \\
\hline RB-10 & 0.012 & 41.6 & 48.1 & 0.158 & 12.7 \\
\hline RB-12 & 0.013 & 45.8 & 52.6 & 0.139 & 11.0 \\
\hline RB-14 & 0.014 & 52.0 & 58.0 & 0.122 & 8.9 \\
\hline SB1-14 & 0.014 & 51.5 & 57.3 & 0.112 & 8.0 \\
\hline SB2-10 & 0.013 & 41.1 & 47.5 & 0.136 & 10.6 \\
\hline SB3-12 & 0.014 & 46.3 & 52.0 & 0.122 & 8.8 \\
\hline SB1-12 & 0.013 & 46.0 & 52.9 & 0.141 & 11.2 \\
\hline SB2-14 & 0.014 & 52.1 & 58.1 & 0.123 & 8.9 \\
\hline SB3-10 & 0.013 & 41.3 & 46.7 & 0.120 & 9.0 \\
\hline
\end{tabular}

Note: ${ }^{(1)}$ the curvature ductility of the beam section was calculated by $\phi_{u} / \phi_{y}$.

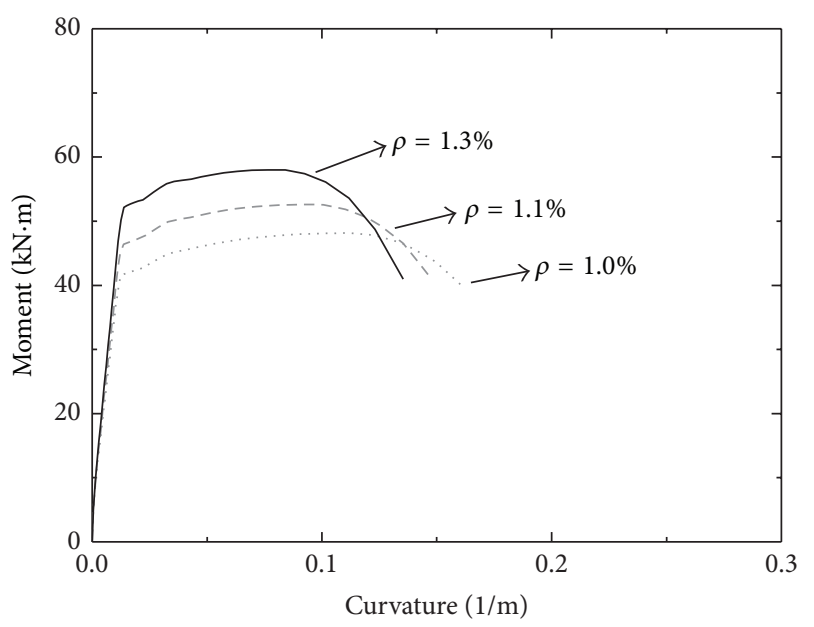

..... RB-10
--- RB-12
- RB-14

Figure 7: Moment curvature curves of the solid beams.

curves of the corresponding entire slotted beam are also given for the purpose of comparison.

For SB1-12, the ductility of the moment curvature curves of beam $\mathrm{A}$ and beam $\mathrm{B}$ was almost the same, and the tensile reinforcement ratio of beam A and beam B of SB214 was $1.1 \%$ and $1.3 \%$, respectively, similar to each other. Similar phenomenon was also found for SB2-14. The similar reinforcement ratio resulted in the fact that the heights of the compression region of beam $\mathrm{A}$ and beam $\mathrm{B}$ at the concrete crush point were almost equivalent to each other [12]. Hence, the ultimate curvature of beam A and beam B of SB1-12/SB214 was nearly the same, because the height of the section was identical for all beams.

For SB2-10, SB3-10, and SB3-12, the ductility of the moment curvature curves of beam $\mathrm{B}$ was obviously greater than that of the corresponding beam $\mathrm{A}$, due to the fact that the reinforcement ratio of beam $B$ was much less than that of the corresponding beam A. For SB1-14, the ductility of beam $B$ for SB1-14 was smaller than that of beam A, because the reinforcement ratio of beam $B$ was larger than that of beam
A. In Figures $8(\mathrm{a}), 8(\mathrm{~b}), 8(\mathrm{~d})$, and $8(\mathrm{e})$, it can be found that the ductility of the entire slotted beam was determined by the beam, of which the ductility was worse than the other part. Therefore, the ductility of both beam A and beam B should be considered and designed carefully in the application of slotted beams in practical engineering.

It should be noted that the width ratio $b_{\mathrm{A}} / b_{\mathrm{B}}$ of SB1-12 was 2.1 , which was the largest width ratio in the tests. However, the ductility of SB1-12 and RB-12 was nearly the same. For SB312 , the width ratio of beam A and beam B was 1.1, which was the smallest width ratio in the tests. However, the ductility of SB3-12 and RB-12 was obviously different. Therefore, it can be concluded that the reinforcement ratio rather than the width ratio of beam $A$ to beam $B$ is the key factor affecting the ductility behavior of the slotted beams.

The moment curvature curves of the slotted beams and corresponding solid beams are shown in Figure 9. The moment curvature curves of SB1-12 and RB-12 were almost coincident, because the reinforcement ratio of RB-12 and the two parted beams of SB1-12 were almost the same. Similar phenomenon was also found for SB2-14 and RB14. In Figure 9(a), it can be clearly found that the larger the difference between $\rho_{\mathrm{A}}$ and $\rho_{\mathrm{B}}$, the worse the ductility of the slotted beam. Therefore, the two parted beams of the slotted beam should be designed to pose similar tensile reinforcement ratio, in order to achieve a similar ductility capacity of the corresponding solid beam.

3.4. Load Capacity Analysis. The flexural capacities of RC beams can be determined when the geometry, the reinforcement, and the strength of the material are known. The flexural capacities of the solid and slotted beams, calculated according to the concrete code of China [13], are given in Table 6, where the experimental results are also given. In Table 6, $M_{\text {cap }}^{\text {exp }}$ is yield capacity of the beams obtained from experiments and $M_{\text {cap }}^{\text {cal }}$ is theoretically calculated flexural capacity of the beams. Because the yield strength of the steel rebar is used to calculate the flexural capacity of the beam in the concrete code, the yield capacities of the beams obtained from the tests were used for the comparison with the theoretically calculated values. 

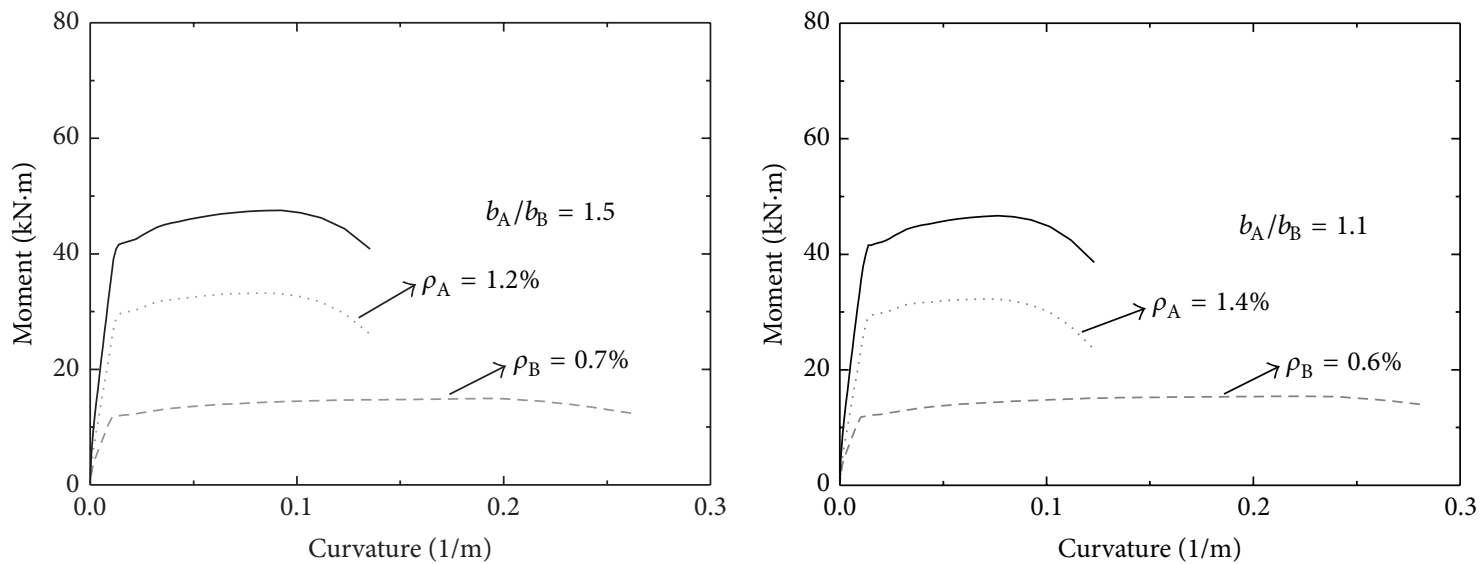

B2-10 beam A

- - SB2-10 beam B

- SB2-10

(a)

-10 beam $A$

- - - SB3-10 beam B

- SB3-10

(b)
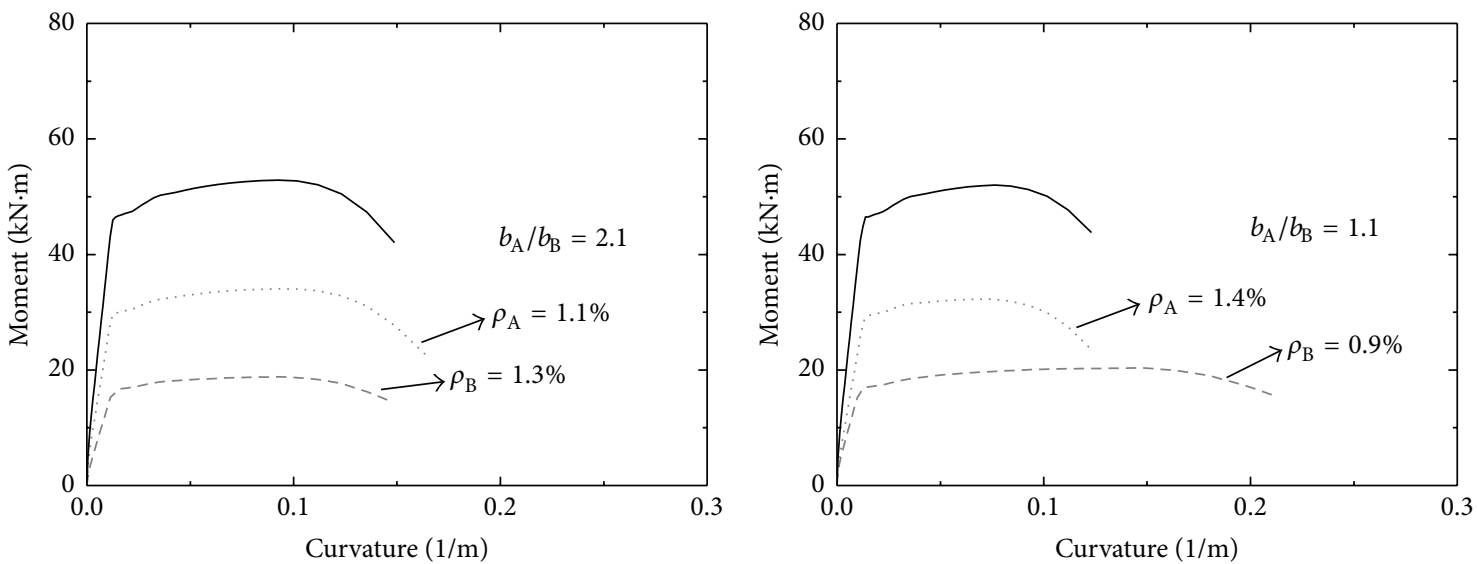

SB1-12 beam A

SB3-12 beam $A$

- - - SB3-12 beam $B$

- SB3-12

(c)
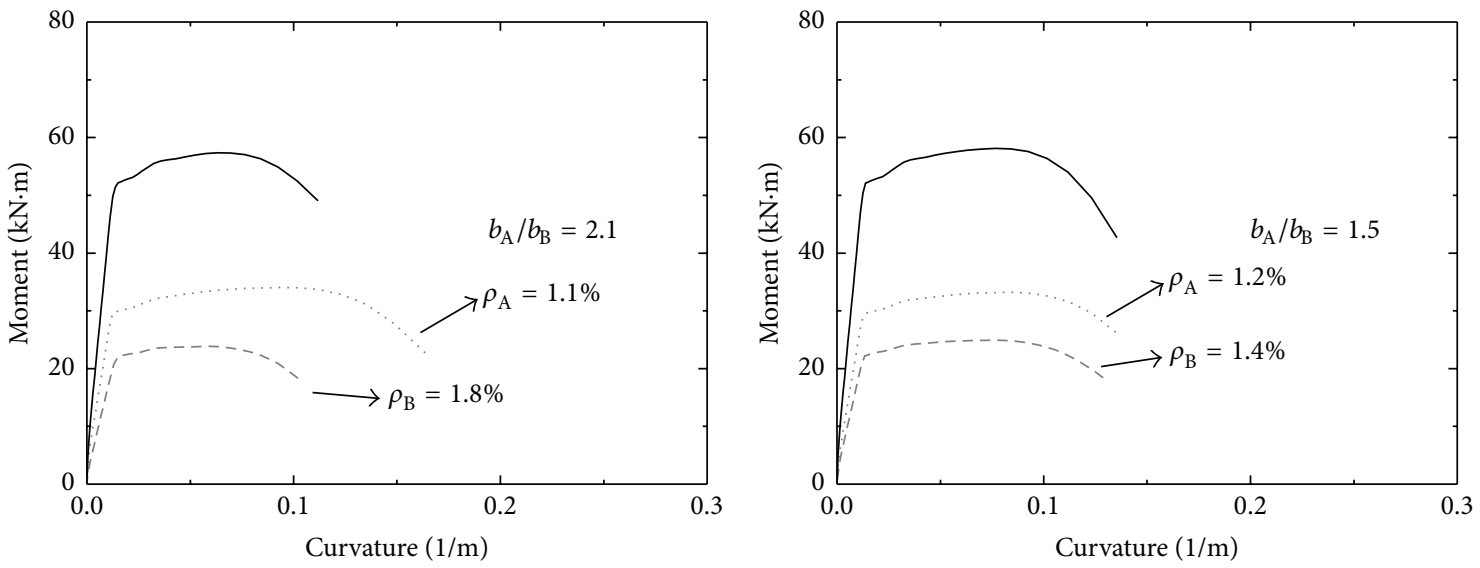

SB1-14 beam A

SB1-14 beam B

SB2-14 beam A

- - - SB2-14 beam B

- SB2-14

(e)

(f)

Figure 8: Moment curvature curves of the slotted beams: (a) SB2-10; (b) SB3-10; (c) SB1-12; (d) SB3-12; (e) SB1-14; and (f) SB2-14. 


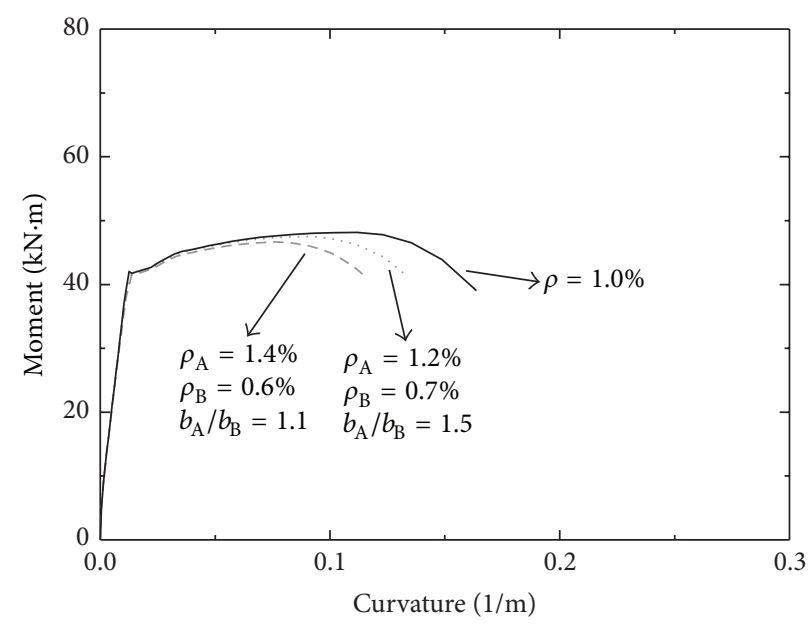

SB2-10

SB3-10

RB-10

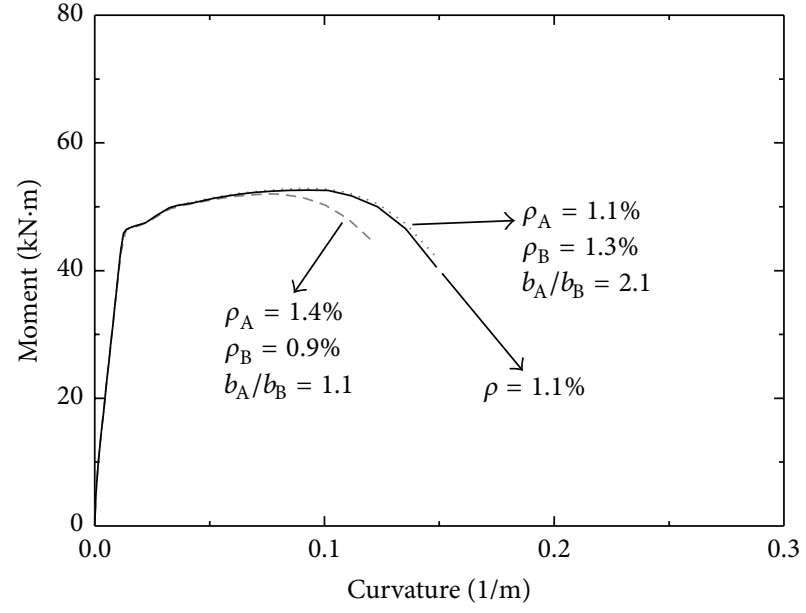

SB1-12

SB3-12

RB-12

(a)

(b)

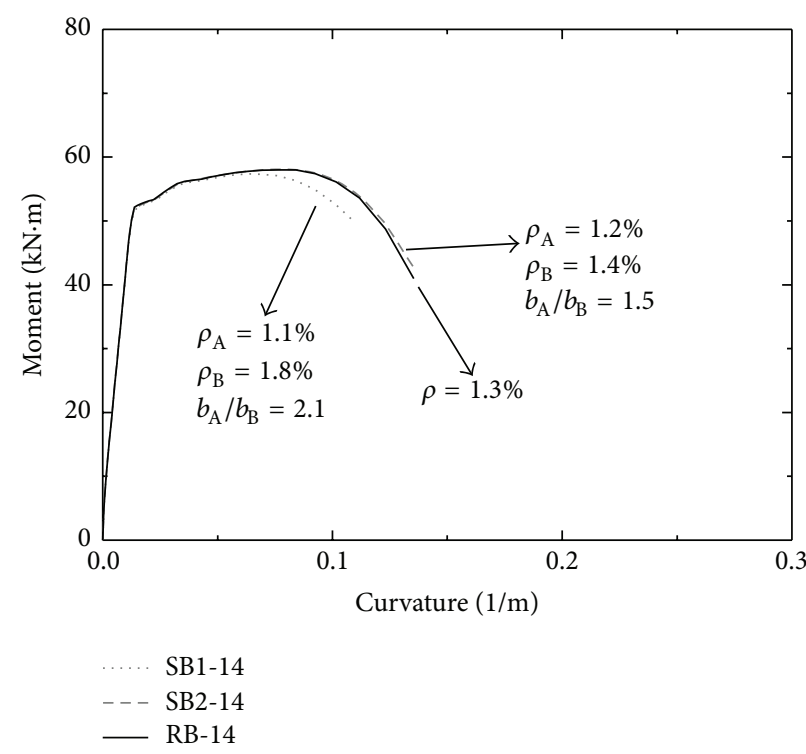

(c)

FIGURE 9: Comparison of the moment curvature curves of the slotted beams and corresponding solid beams: (a) SB2-10, SB3-10, and RB-10; (b) SB1-12, SB3-12, and RB-12; and (c) SB1-14, SB2-14, and RB-14.

Table 6 shows that the calculated flexural capacity $M_{\text {cap }}^{\text {cal }}$ was close to the value obtained from the tests for both the solid and slotted beams, indicating that the method used in the code was effective in predicting the flexural capacity of these two types of beams. Meanwhile, the calculated flexural capacities were conservative compared with the test results. It was found that the sum of the flexural capacities of beam A and beam B of the slotted beams was equal to that of the corresponding solid beam. This observation was coherent with the phenomena shown in Figure 6, where it was found that the load-deflection curves of the solid beam and slotted beam were close to each other before the descending branch. However, it should be noted that the slotted beam exhibited decreased ductility capacity compared with the corresponding solid beam, as discussed in Section 3.2.

\section{Structural Design Advices for the Slotted RC Beams}

Based on the above experimental results and analysis, several design advices can be made for the slotted RC beams, in order to obtain favourable mechanical behavior:

(1) The target failure mode of the slotted RC beam should be typical flexural failure mode, in order to ensure sufficient ductility. Therefore, sufficient tensile 
TABLE 6: Yield capacities of the specimens.

\begin{tabular}{lcccc}
\hline Specimen identifier & $M_{\text {cap }}^{\text {exp }}(\mathrm{kN} \cdot \mathrm{m})$ & & $M_{\text {cap }}^{\text {cal }}(\mathrm{kN})$ & $M_{\text {cap }}^{\text {exp }} / M_{\text {cap }}^{\text {cal }}$ \\
\hline RB-10 & 44.4 & & 40.8 & 1.09 \\
RB-12 & 48.6 & & 45.6 & 1.07 \\
RB-14 & 57.9 & Beam A & Beam B & Beam A + beam B \\
\hline & & 29.4 & 22.2 & 51.6 \\
\hline SB1-14 & 58.3 & 29.4 & 11.4 & 40.8 \\
SB2-10 & 49.5 & 29.4 & 16.2 & 45.6 \\
SB3-12 & 48.5 & 29.4 & 16.2 & 45.6 \\
SB1-12 & 51.2 & 29.4 & 22.2 & 51.6 \\
SB2-14 & 55.9 & 29.4 & 11.4 & 4.13 \\
SB3-10 & 44.6 & & & 1.06 \\
\hline
\end{tabular}

reinforcement is needed at the bottom of the beam. Meanwhile, sufficient stirrup reinforcement for shear is also needed in order to prevent shear failure.

(2) The ductility of beam A and ductility of beam B of a slotted beam should be close to each other in order to insure that these two beams underwent similar damage process under flexural load and reach the final failure nearly at the same time. In order to achieve the above flexural behavior of a slotted beam, the reinforcement ratios of beam $\mathrm{A}$ and beam $\mathrm{B}$ should be close to each other.

(3) In addition, the concrete strength, the span limitation, and the ratio of beam width to beam height should meet the current specification requirement for reinforced beam in the code.

\section{Thermal Insulation Behavior of the Slotted Beams}

Thermal performance is an important parameter to evaluate the feasibility of the slotted beam as a thermal insulation structural component. The heat transfer coefficient is a frequently used index to evaluate the thermal properties of materials. This index is influenced by the thermal conductivity and thickness of the materials through which heat is transferred. The heat transfer coefficient $K$ of the slotted beam can be calculated using the following equations based on the thermal deign code for civil building in China [14]:

$$
\begin{aligned}
R & =\frac{\delta_{\mathrm{A}}}{\lambda_{c}}+\frac{\delta_{\text {insul }}}{\lambda_{\text {insul }}}+\frac{\delta_{\mathrm{B}}}{\lambda_{c}}, \\
R_{0} & =R_{\text {in }}+R+R_{\text {out }}, \\
K & =\frac{1}{R_{0}},
\end{aligned}
$$

where $R$ is sum of thermal resistance values of all the material layers for the slotted beam; $\delta_{\mathrm{A}}, \delta_{\text {insul }}$, and $\delta_{\mathrm{B}}$ are thickness of beam $A$, the thermal insulation layer, and beam $\mathrm{B}$, respectively; $\lambda_{c}$ and $\lambda_{\text {insul }}$ is thermal conductivity of the concrete and the thermal insulation layer, respectively; $R_{0}$ is thermal resistance value of the slotted beam; $R_{\text {in }}$ and $R_{\text {out }}$ is thermal resistance of the inner and outer surface against heat convection, respectively, and are set to be $0.11 \mathrm{~m}^{2} \cdot \mathrm{K} / \mathrm{W}$ and $0.04 \mathrm{~m}^{2} \cdot \mathrm{K} / \mathrm{W}$, respectively, based on the thermal design code for civil building in China [14]; and $K$ is heat transfer coefficient of the beam. The larger the coefficient is, the easier the heat is transferred through the beam. For the solid beam, (1) is changed to $R=\delta_{c} / \lambda_{c}$ and the calculation process becomes simpler.

Thermal inertia index, as a dimensionless quantity, represents the resistance of the material to variations in temperature. The thermal inertia index $D$ of the slotted beam can be computed using the following equation [14]:

$$
D=\frac{\delta_{\mathrm{A}}}{\lambda_{c}} S_{c}+\frac{\delta_{\text {insul }}}{\lambda_{\text {insul }}} S_{\text {insul }}+\frac{\delta_{\mathrm{B}}}{\lambda_{c}} S_{c},
$$

where $S_{c}$ and $S_{\text {insul }}$ are thermal storage coefficient of the concrete and the thermal insulation layer. Materials with high thermal inertia show small changes in temperature under the effect of outer environmental temperature, showing good heat insulation effect. From (1), it is easy to find that, for the slotted beam with a certain sum width of beam $A$ and beam $B$, the width ratio of beam $A$ to beam $B$ has no effect on the thermal resistance value $R$ and only $\delta_{\text {insul }}$ and $\lambda_{\text {insul }}$ of the thermal insulation layer have effect on $R$. Similarly, only $\delta_{\text {insul }}$, $\lambda_{\text {insul }}$, and $S_{\text {insul }}$ have effect on the thermal inertia index of the slotted beam when the sum width of beam A and beam B is determined.

Rigid extruded polystyrene foam board, also called XPS, can provide excellent insulation against both cold and heat and has the following advantages: high corrosion resistance, moisture proof, light weight, and antiaging capacity. Hence, XPS has been widely used as thermal insulation material in practical engineering. In this paper, XPS was used to fill the gap in the slotted beams. In addition to XPS, it should be noted that other insulation materials can also be used as the thermal insulation layer in the slotted beam. The values of $\lambda$ and $S$ for reinforced concrete and XPS recommended in the Chinese code $[14,15]$ are given in Table 7 . The thermal calculation result of the beams is given in Table 8 . It can be seen that the heat transfer coefficient of the slotted beam decreases by $77.4 \%$ compared with the solid RC beam. The thermal inertia factor of the slotted beam is 2.83 , higher than that of the solid beam, 2.47. These data indicate that the 
TABLE 7: Thermophysical parameters of the materials.

\begin{tabular}{lcc}
\hline Material type & Thermal conductivity $\lambda(\mathrm{W} /(\mathrm{m} \cdot \mathrm{K}))$ & Thermal storage coefficient $S(\mathrm{~W} /(\mathrm{m} \cdot \mathrm{K}))$ \\
\hline Reinforced concrete & 1.74 & 17.2 \\
XPS & 0.03 & 0.36 \\
\hline
\end{tabular}

TABLE 8: Thermal calculation results of the beams.

\begin{tabular}{lccc}
\hline Beam type & Thermal resistance $R\left(\mathrm{~m}^{2} \cdot \mathrm{K} / \mathrm{W}\right)$ & Heat transfer coefficient $K\left(\mathrm{~W} /\left(\mathrm{m}^{2} \cdot \mathrm{K}\right)\right)$ & Thermal inertia factor $D$ \\
\hline Solid beam & 0.29 & 3.45 & 2.47 \\
Slotted beam & 1.29 & 0.78 & 2.83 \\
\hline
\end{tabular}

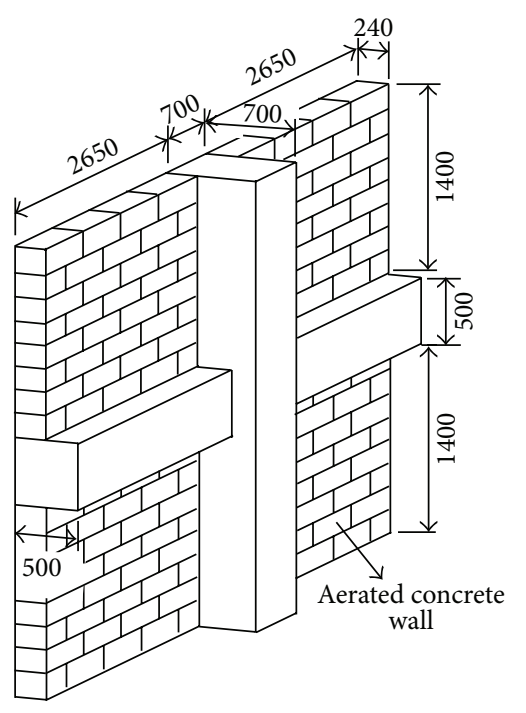

(a)

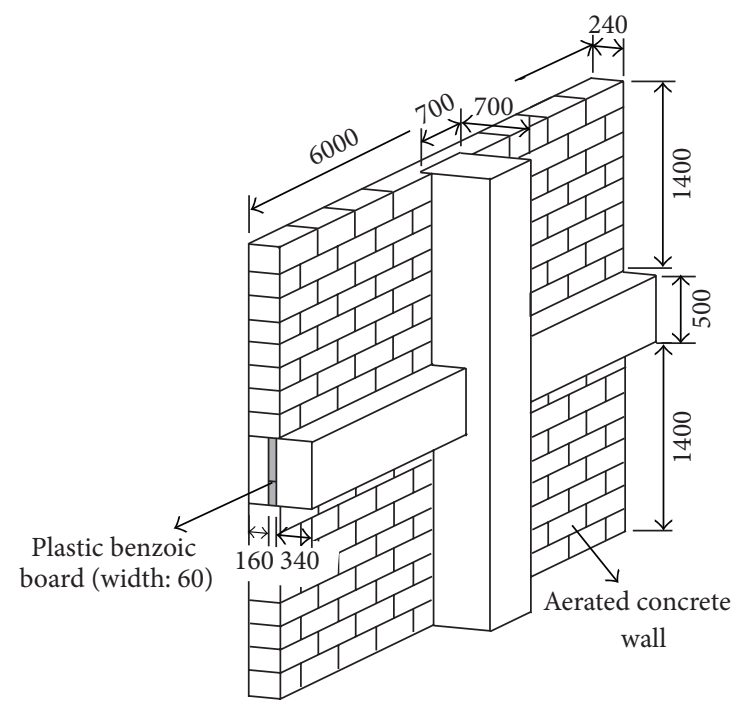

(b)

FIGURE 10: Geometry of the unit frame built in COMSOL Multiphysics: (a) normal frame and (b) frame using the slotted beam-wall system (units: $\mathrm{mm}$ ).

thermal bridge of the slotted beam is effectively mitigated and the thermal performance of the slotted beam becomes much better than that of the conventional solid RC beam.

\section{Thermal Insulation Behavior of the Slotted Beam-Wall System}

6.1. FEM Model Building. A FEM software, COMSOL Multiphysics [16], which has passed the model tests required by the European standard EN 10211: 2007 for thermal bridges in building constructions [17] and was found to be suitable for simulating the heat transport through buildings [18], was used to simulate the thermal insulation behavior of the frame structure using the slotted beam-wall system. The thermal insulation behavior of this new type of structure in winter was considered in the FEM model and a normal frame structure FEM model was also built for comparison purpose. The temperatures inside and outside the room are set to $18^{\circ} \mathrm{C}$ and $0^{\circ} \mathrm{C}$, respectively, according to the design standard for energy efficiency of residential buildings in hot summer and cold winter zone in China [19]. These temperatures are typical for the buildings using heating in the south area of
China in winter. The plan and elevation layout are always regular for residential frame buildings; therefore only one unit of the frame was modeled in COMSOL due to the symmetrical structure of the frame structure, for the purpose of conciseness. The dimension information of the frame FEM model is shown in Figure 10, where the beam span, the floor height, and the size of columns and beams are typical for 10-story height residential frame buildings in China. The exterior vacuum insulation windows, beam perpendicular to the exterior wall, and the floor slabs were not modeled, in order to make the comparison of the thermal properties between the normal frame and frame using the slotted beamwall system more specific. The boundary condition of the four sides of the model was thermal insulation, due to the symmetry of the model. 3D steady state thermal bridge was considered in COMSOL analysis, meaning the field variables are independent of time. More detailed modeling and analysis process can be referred to in COMSOL user manual. Thermophysical parameters of the materials used in the FEM model are given in Table 9 and it is assumed that these thermal properties are independent of the temperature during the FEM analysis. 
TABLE 9: Thermophysical parameters of the materials.

\begin{tabular}{lcccc}
\hline Material type & Density $\left(\mathrm{kg} / \mathrm{m}^{3}\right)$ & $\begin{array}{c}\text { Thermal conductivity } \\
(\mathrm{W} /(\mathrm{m} \cdot \mathrm{K}))\end{array}$ & $\begin{array}{c}\text { Thermal storage } \\
\text { coefficient }\left(\mathrm{W} /\left(\mathrm{m}^{2} \cdot \mathrm{K}\right)\right)\end{array}$ & $\begin{array}{c}\text { Heat capacity } \\
(\mathrm{J} /(\mathrm{kg} \cdot \mathrm{K}))\end{array}$ \\
\hline Reinforced concrete & 2500 & 1.74 & 17.20 & 920 \\
XPS & 30 & 0.03 & 0.36 & 1380 \\
Aerated concrete wall & 500 & 0.19 & 2.81 & 1050 \\
\hline
\end{tabular}

TABLE 10: Comparison of the FEM simulation results.

\begin{tabular}{lccccc}
\hline Structure type & $\begin{array}{c}\text { Heat transfer area } \\
\left(\mathrm{m}^{2}\right)\end{array}$ & $\begin{array}{c}\text { Total heat flux } \\
(\mathrm{W})\end{array}$ & $\begin{array}{c}\text { Heat flux on walls } \\
(\mathrm{W})\end{array}$ & $\begin{array}{c}\text { Heat flux on } \\
\text { columns }(\mathrm{W})\end{array}$ & $\begin{array}{c}\text { Heat flux on } \\
\text { beams }(\mathrm{W})\end{array}$ \\
\hline Normal RC frame & 19.8 & 460.3 & 224.1 & 102.2 & 134.0 \\
RC frame using slotted beams & 19.8 & 287.1 & 201.7 & 49.4 & 36.1 \\
\hline
\end{tabular}

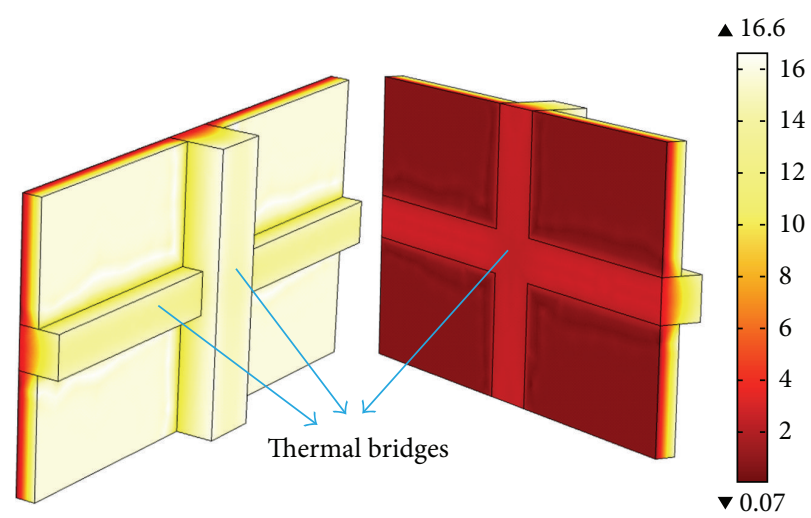

(a)

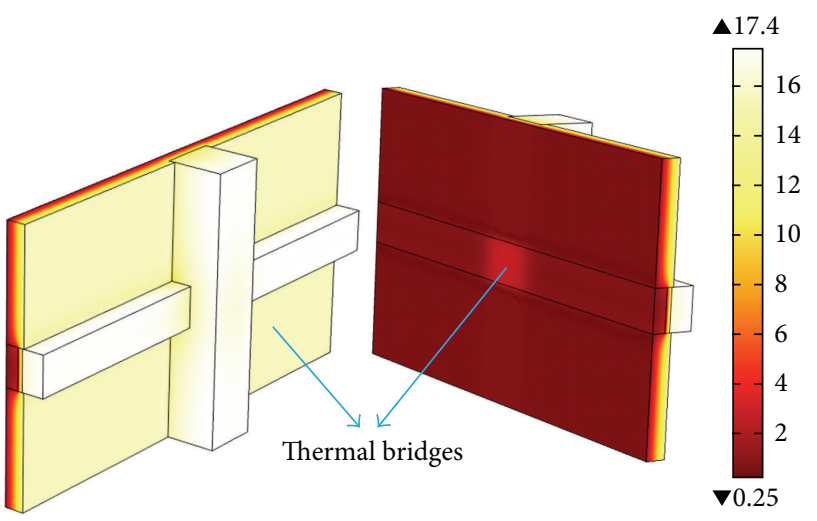

(b)

FIGURE 11: Surface temperature distribution of the FEM models (units: $\left.{ }^{\circ} \mathrm{C}\right)$ : (a) normal frame and (b) frame using the slotted beam-wall system.

6.2. Simulation Result and Discussion. The temperature distribution on the surfaces of the FEM models is shown in Figure 11. It is obvious that the beams and columns constitute the thermal bridges for the normal frame in Figure 11(a). However, the thermal bridges have been controlled after the slotted beam-wall system have been utilized, as shown in Figure 11(b), where the location of beam-column joint becomes the thermal bridge. In fact, this thermal bridge can be reduced in practical engineering because it is easy to carry out heat insulation treatment on this small area.

The results of the calculated heat flux are given in Table 10. The heat flux in the normal frame and frame using the slotted beam-wall system was $460.3 \mathrm{~W}$ and $287.1 \mathrm{~W}$, respectively. The heat flux through the beams and columns in the normal frame structure was $236.2 \mathrm{~W}$ ( $51.3 \%$ of the total heat flux of the normal structure), indicating that the thermal bridge effect was obvious in the normal frame structure. However, the heat flux through the beams and columns in the frame using the slotted beam-wall system was $85.5 \mathrm{~W}$ (29.8\% of the total heat flux of this new type structure). The thermal bridge effect has been controlled in the new frame structure through using the slotted beam-wall system. In addition, though the area of the walls of this new type structure was larger than that of the normal frame, the heat flux on the walls of this new type structure was $22.4 \mathrm{~W}$ less than that of the normal frame.

\section{Conclusions}

In this study, a novel slotted beam-wall system was proposed for thermal insulation of RC frame buildings. Four-point bending test was carried out to investigate the flexural behavior of the slotted beams. The flexural behavior of the slotted beams was investigated in detail, including failure mode, load-deflection curves, and moment curvature analysis. Thermal insulation behavior of the slotted beam was analyzed through theoretical calculation. Finally, the thermal behavior of the frame using the slotted beam-wall system was simulated through FEM method. The following conclusions can be drawn:

(1) Though the final failure mode of the slotted beams was flexural failure mode, the failure process of the slotted beams was different from that of the solid beams at the final loading stage.

(2) Before the final failure stage, the load-deflection curve of the slotted beam was close to that of its corresponding solid beam. The tensile reinforcement ratio rather 
than the width ratio of the two parted beams had an important effect on the flexural behavior of the slotted beams. The tensile reinforcement ratios of the two parted beams of a slotted beam should be close to each other, in order to obtain similar ductility behavior of their corresponding solid beam.

(3) The slotted beams exhibited attractive thermal insulation properties. The heat transfer coefficient of the slotted beam was greatly reduced and the thermal inertia factor increased, compared with the corresponding solid beams. Hence, the slotted beam has a great potential for the practical thermal insulation application of RC frame buildings.

(4) The FEM simulation results showed that the frame structure using the slotted beam-wall system exhibited obvious and attractive thermal insulation property, compared with the normal frame structure. It is believed that this new type of structure can become an effective measure to solve the thermal insulation problem.

\section{Competing Interests}

The authors declare that they have no competing interests.

\section{Acknowledgments}

This research was sponsored by the Science and Technology Plan of Changsha, China (Grant no. CSCG-HNTFGK20130576), the National Natural Science Foundation of China (Grant no. 51408211), the Natural Science Foundation of Hunan Province, China (Grant no. 2015JJ3032), the Fundamental Research Funds for the Central Universities through the project of Young Teacher Growth of Hunan University (Grant no. 531107040799), and the Open Fund of Hunan Province Engineering Laboratory of Bridge Structure (Changsha University of Science \& Technology, Grant no. 14KD02).

\section{References}

[1] J. Iwaro and A. Mwasha, "A review of building energy regulation and policy for energy conservation in developing countries," Energy Policy, vol. 38, no. 12, pp. 7744-7755, 2010.

[2] B. P. Jelle, "Traditional, state-of-the-art and future thermal building insulation materials and solutions-properties, requirements and possibilities," Energy and Buildings, vol. 43, no. 10, pp. 2549-2563, 2011.

[3] T. G. Theodosiou and A. M. Papadopoulos, "The impact of thermal bridges on the energy demand of buildings with double brick wall constructions," Energy and Buildings, vol. 40, no. 11, pp. 2083-2089, 2008.

[4] K. S. Al-Jabri, A. W. Hago, A. S. Al-Nuaimi, and A. H. Al-Saidy, "Concrete blocks for thermal insulation in hot climate," Cement and Concrete Research, vol. 35, no. 8, pp. 1472-1479, 2005.

[5] S. Kumar, "Fly ash-lime-phosphogypsum hollow blocks for walls and partitions," Building and Environment, vol. 38, no. 2, pp. 291-295, 2003.
[6] J. Wang, P. C. Eames, J. F. Zhao, T. Hyde, and Y. Fang, "Stresses in vacuum glazing fabricated at low temperature," Solar Energy Materials and Solar Cells, vol. 91, no. 4, pp. 290-303, 2007.

[7] N. Ng, R. E. Collins, and L. So, "Thermal conductance measurement on vacuum glazing," International Journal of Heat and Mass Transfer, vol. 49, no. 25-26, pp. 4877-4885, 2006.

[8] N. Ng, R. E. Collins, and L. So, "Characterization of the thermal insulating properties of vacuum glazing," Materials Science and Engineering B, vol. 138, no. 2, pp. 128-134, 2007.

[9] Code of China, Standard for Test Method of Concrete Structures (GB/T 50152-2012), China Architecture \& Building Press, Beijing, China, 2012 (Chinese).

[10] D. C. Kent and R. Park, "Inelastic behaviour of reinforced concrete members with cyclic loading," Bulletin of the New Zealand Society for Earthquake Engineering, vol. 4, no. 1, pp. 108-125, 1971.

[11] B. D. Scott, R. Park, and M. J. N. Priestley, "STRESS-strain behavior of concrete confined by overlapping hoops at low and high strain rates," Journal of the American Concrete Institute, vol. 79, no. 1, pp. 13-27, 1982.

[12] J. K. Wight and J. G. MacGregor, Reinforced Concrete: Mechanics and Design, Pearson Education, 6th edition, 2011.

[13] Code of China, Code for Design of Concrete Structures (GB 50010-2010), China Architecture \& Building Press, Beijing, China, 2010 (Chinese).

[14] Code of China, Thermal Design Code for Civil Building (GB50176-93), China Planning Press, Beijing, China, 1993 (Chinese).

[15] Code of China, "Rigid extruded polystyrene foam board for thermal insulation (XPS)," GB/T 10801.2-2002, Standards Press of China, Beijing, China, 2002 (Chinese).

[16] COMSOL, Multiphysics User's Guide, Comsol AB, Stockholm, Sweden, 2010.

[17] European Committee for Standardization. EN ISO 10211, “Thermal bridges in building construction-heat flows and surface temperatures-detailed calculations," ISO 10211:2007, 2007.

[18] A. W. M. van Schijndel, "Multiphysics modeling of building physical constructions," Building Simulation, vol. 4, no. 1, pp. 49-60, 2011.

[19] Code of China, "Design standard for energy efficiency of residential buildings in hot summer and cold winter zone," JGJ 134-2010, China Architecture \& Building Press, Beijing, China, 2010 (Chinese). 

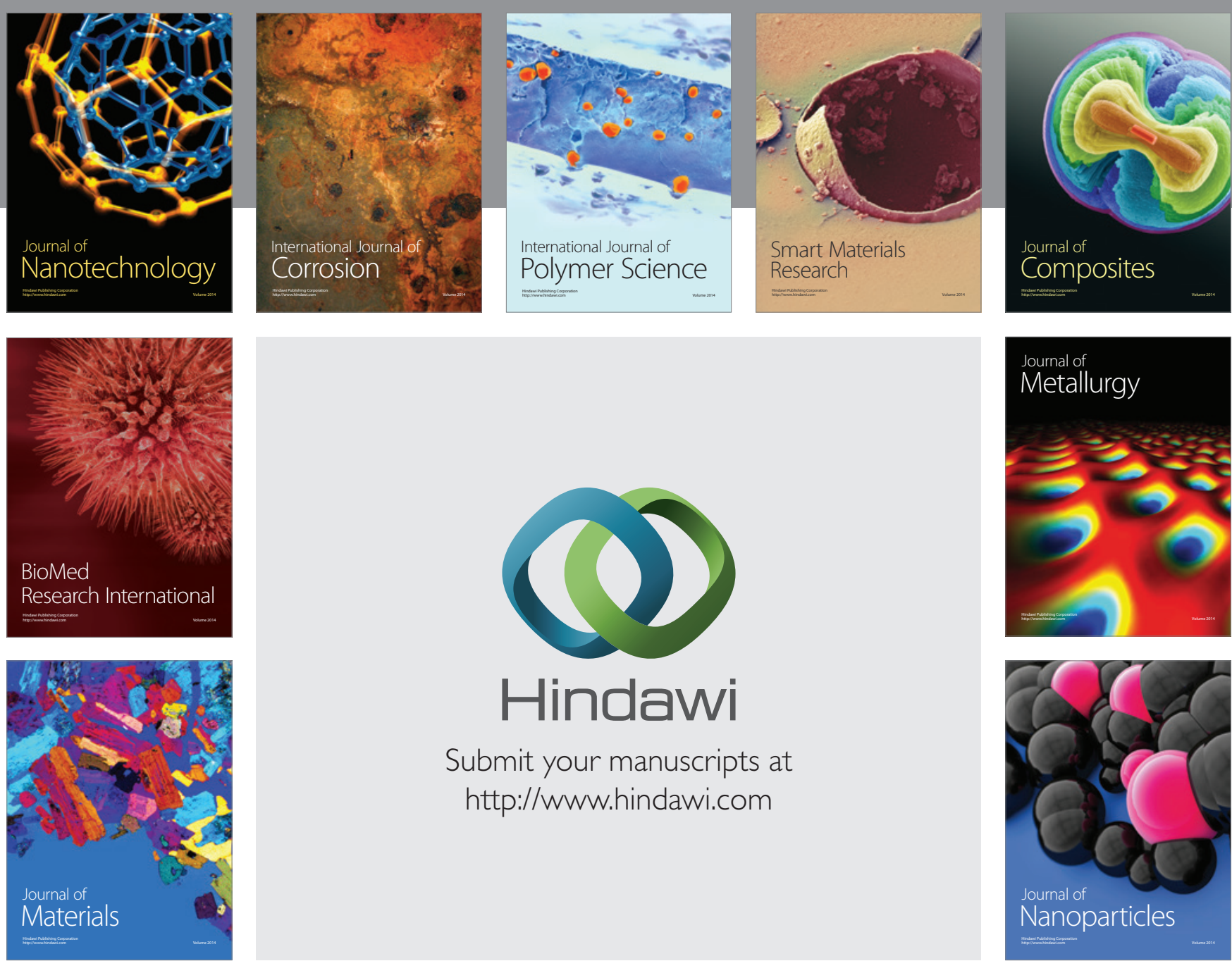

\section{Hindawi}

Submit your manuscripts at

http://www.hindawi.com

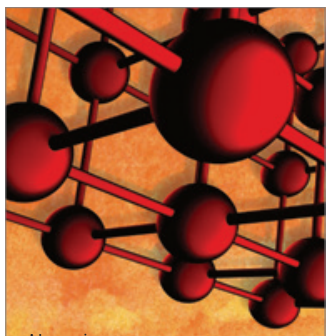

Materials Science and Engineering
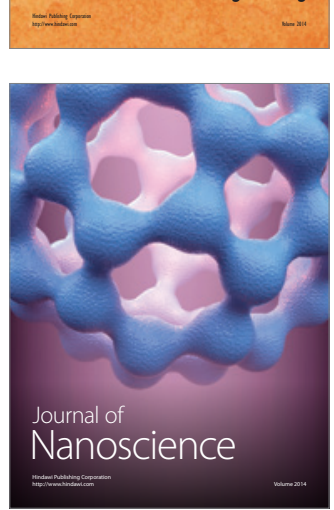
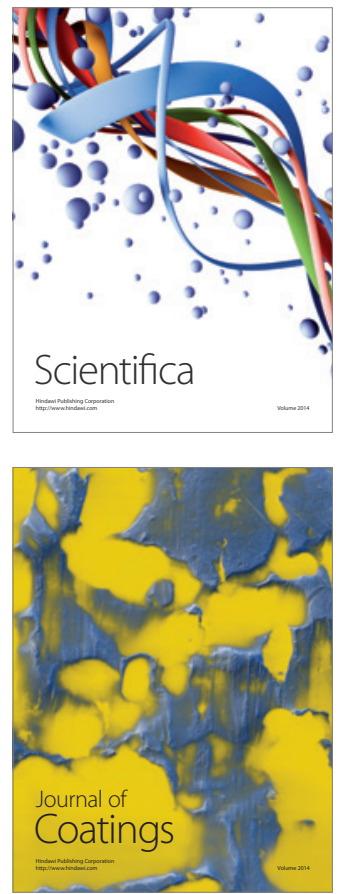
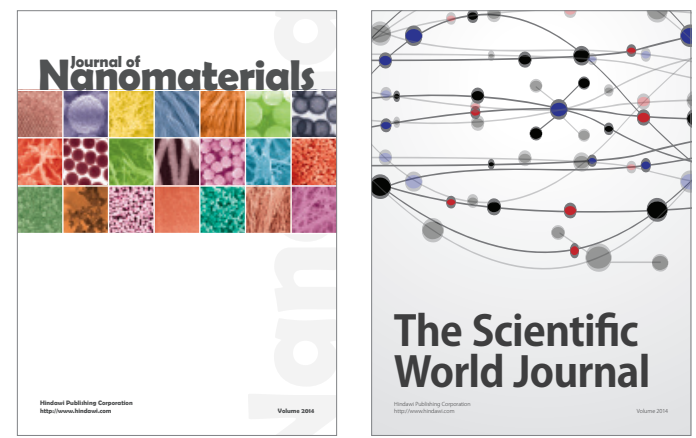

The Scientific World Journal
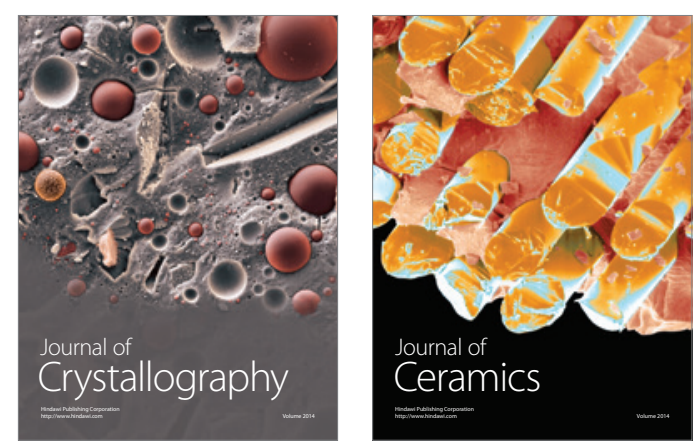
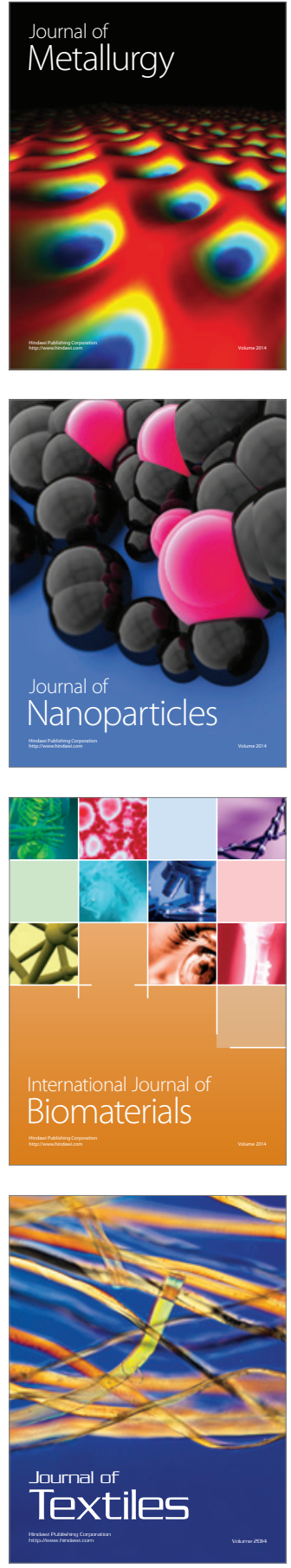